\title{
Motivation in teaching English for specific purposes classes
}

Mamatkarimova Barno -Almaliq branch of Tashkent State Technical

University named after Islam Karimov

Khujayarov Nuriddin - Angren information technology and industrial vocational college

Anotation: Research of experience of professional training of future personnel in modern conditions of reforming provides search of ways of increase of efficiency of teaching of discipline English, since the earliest stage of training - from cadet school. The analysis of the existing scientific works on increasing the effectiveness of training showed that one of the leading factors in the study of a foreign language is motivation. Thus, the purpose of this article is to consider ways to increase the motivation of pupils of the Sevastopol presidential cadet school in the course of studying the discipline English in order to improve the quality of teaching the subject in this institution.

Key words: motivation, foreign language communication, educational and cognitive activity, communicative competence, creative approach, psychology of education.

Modern research in the field of pedagogy and psychology pay a lot of attention to the phenomenon of motivation. Nowadays, the fact that motivation plays a huge role in the study of any subject, especially foreign languages, is generally accepted. However, the study of the problem of increasing motivation in the course of mastering the English language in a secondary military school is a little investigated aspect. Thus, the purpose of this article is to determine ways to increase motivation in the study of English on the example of cadet school students.

It is widely known that English is the official language of international exercises and summits. It is the language of political negotiations and many public organizations. However, as a subject, the ultimate goal of which is mastering the skills of foreign language communication (both oral and written), it has a number of specific features, one of which is mastering the English language by teaching the ability to communicate in a foreign language. Therefore, based on the actual needs and specifics of the subject, the most important factor in teaching speech communication in English is the motivation of learning a foreign language. Considering the basic concepts of motivation, we, following Ia Winter, will rely on the fact that "motive - this is what explains the nature of this speech action, while the communicative intention expresses what communicative purpose is pursued by the speaker, planning a particular form of influence on the listener»».

Regardless of the level and type of educational institution, learning a foreign language, it is necessary to create such conditions in educational and cognitive activities that contribute to the development of the student's high level of cognitive interest in learning English. There are many different opinions on the definition of the types of motives that are formed in students when learning English. For example, V. D. Shadrikov in works on the psychology of education believes that "motivation is due to the needs and goals of the individual, the ideals of man, the 
conditions of his activities (both objective, external and subjective, internal knowledge, skills, abilities, and character)". R. A. Gottlieb believes that "motivation is such a driving force that motivates a person to successfully learn a foreign language". Therefore, the motive is considered as the internal motivation of the student to educational activity caused by personal needs of the student, in particular, individual features of development of his personality.

In the pedagogical literature two types of motives are described in detail: internal and external. Internal - which develop under the influence of the trainee's own thoughts, his aspirations, experiences, the emergence of certain needs, resulting in an awareness of internal necessity. However, the analysis of the experience of teaching this discipline in the Sevastopol presidential cadet school showed that not all cadets at the time of admission to the military school were formed only positive motives for learning English, due to the study of another foreign language in their primary school. Thus, the primary task of the teacher of the presidential corps is to reduce the level of influence of negative motivation and stimulate positive motives for the study of discipline.

Another factor of the negative impact on the development of positive dynamics of motivation is the different level of English proficiency of cadets at the time of admission to the Sevastopol cadet school. I. e. based on the existing realities, the so-called mixed-abilities groups (groups of mixed level of knowledge) are formed. In this case, the primary task of the teacher is to "align" the level of knowledge of students by conducting additional classes with weaker students, as well as those who previously studied another foreign language; organization of individual work in the group; organizations "curating" stronger students over the weak.

From the very beginning of the English language course, the teacher needs to clearly define the line of motivation and the scope of the English language in the future professional activities of students. During the analysis of scientific and methodical literature, as well as materials of the periodical press, the main directions of the use of the English language in the modern military environment were identified.

In modern conditions of reforming of Armed Forces of the Russian Federation there are significant transformations and structural and functional changes that to a large extent entails change of the concept of military education in this connection new requirements "to professionalism, technical Outlook and competence of military of the most modern level" [4] are imposed. Today, one of the priorities of military education is the formation of a future officer with high moral and professional qualities, able to act quickly and efficiently in the military environment, both in our country and abroad. In this situation, it is imperative to be tolerant to the culture and traditions of other countries, which is achieved through careful study of a foreign language. Modern military specialist should have not only military-special knowledge, but also to understand the modern picture of the world.

The importance of the English language for the military has grown significantly in recent decades, this growth is largely the result of two factors: 
changes in the role of the military and changes in defense. All armed forces are now more actively involved in providing humanitarian assistance and peacekeeping operations, including international ones. It is necessary as soon as possible to begin to develop linguistic thinking (the ability to think in English), to reason logically, to be able to clearly Express their thoughts, using all the expressive means of language; use English as a means of obtaining and exchanging information, using a computer and the Internet to gain knowledge in various fields of science and technology, using various programs to perform calculations. In the Sevastopol presidential cadet school, all the necessary conditions have been created for the implementation of the above tasks, starting with the first year of study at the school - from the 5th grade.

Based on the specifics of this institution, it is necessary not only to teach the pupil English as a tool of communication, but also to instill all the skills that will be necessary in the future career of a soldier. To implement these tasks, it is necessary to identify a number of main factors that contribute to the formation of the pupil of the cadet school positive motives for learning English, the main of which, in our opinion are: understanding the goals of training; professionallyoriented content of educational material; the development of cognitive abilities of cadets; the interest of the subject; an emotional form of lessons by the teacher; the teacher setting challenging, developing the ability to think independently and make the decision of tasks contributing to the development of creative activity of students; awareness of the importance of acquired knowledge; assessment knowledge; the formation of applied language learning purposes.

Some researchers believe that external motives are not related to the content of the educational material. These include: duty, duty (the student must study the subject to get a positive assessment); assessment (the desire to score as many points per quarter). However, it should take into account not only the mark for the knowledge of a particular educational material, but also the motivating role of the pupil, which is very large. Cognitive motivation is most important in learning a foreign language. However, it is necessary that it became the main for the development of professional orientation of cadets, stimulated their educational activity, good academic performance, positive attitude to the studied language. Attitude to the English language largely depends on the assessment of the importance of their professional training in the specialty. Cognitive motive in mastering the English language is explained by the correct organization of educational activities, taking into account the professional orientation of the cadets, using a variety of methods of teaching, as well as an objective assessment of knowledge of students. An important role in increasing the motivation of cadets, especially at the initial stage of training (5th, 6th grades), is played by various types of work used by the teacher in the lesson: lessons-discussions of different topics; lessons-communication with cadets on the Internet (effective as an option of self-training); round tables; mini-conferences in groups; lessons-tests; lessons online; lessons-presentations, as well as video lessons. Lessons aimed at training cadet school students to make presentations in English on both General and 
military topics (taking into account the age criterion of students) are of significant importance in recent years.

Teachers of the cadet school during the lesson of English are widely used elements of country studies, which allows students to learn more about the culture of the countries of the target language, their traditions. Also, the positive motivation was influenced by the use of not only educational, adapted literature, but also authentic materials. Based on the fact that the ultimate goal of learning is fluency in communication skills, the use of authentic materials demonstrates a vivid example of the original speech, which should strive for every student of a foreign language. Speaking about the forms of classes, special attention in the lesson deserves a form such as role-playing. This type of training is a group activity, which is very valuable in the process of formation of a military team. Role-playing game is based on joint actions, collective form carry quests. In this work, the leading role is given not to the teacher, but to the cadets. Thus, even in the walls of secondary school there is the development of such qualities of the future military personality as will, organization, resourcefulness, initiative. Roleplaying game provides ability to be guided in the behavior by interests of companions, stimulates interest in improvisation, forces to make independent decisions. All this also, of course, awakens interest in the subject and stimulates positive motivation.

As a promising direction of learning English teachers cadet school consider the introduction of computer technology in the educational process, as they contribute to a more effective formation of foreign language communicative competence of students and play an important role in the development of positive motivation of learning: develop the necessary communication skills in various types of speech activity, in an entertaining form, present socio-cultural information about the country of the language, form the basis of independent learning. From a psychological point of view, computer-aided foreign language teaching significantly increases the level of motivational readiness to learn a foreign language, creates a psychologically comfortable atmosphere in the classroom, provides a greater degree of interactivity in communication and adaptability to the needs of a particular student.

From the psychological point of view, computer-aided learning of a foreign language significantly increases the level of motivational readiness to learn a foreign language, creates a psychologically comfortable atmosphere in the classroom, provides a greater degree of interactivity in communication and adaptability to the needs of a particular student [6]. Thus, analyzing the existing opportunities for learning English, it is possible to conclude that the effectiveness of the process of learning a foreign language depends not only on the willingness of the teacher and students and on the modern technological solutions that will be used in the classroom, but also on the ability of the teacher to justify the need to study the subject and to implement a creative approach to teaching this discipline. 


\section{Literature:}

1. Gottlieb R. A. Social demand for knowledge of a foreign language. Sociological research, No

2. February 2009, pp. 122-127. 2. Delvig N. A. Theoretical and methodological basis for the formation of bilingual competence of future officers in the conditions of the naval University of the Russian Federation. Science. of so. Doct topics. Diss. Yalta, 2014.

3.

Winter I. A. Pedagogical psychology. - Rostov-on-don: Phoenix,1997.-480s

4. Qualitatively different country. Russian newspaper. — 2008. - 9 Feb. № 4585

5. Semenova T. V., Semenova M. V. Role-playing games in teaching foreign languages.// Foreign languages at school. — 2005. - № 1 .

6. Solopova E. V. Formation of foreign language communicative competence of younger students using a computer in the learning process. Author's abstract on competition of a scientific degree of candidate of pedagogical Sciences. Yelets, 2008. - $20 \mathrm{p}$.

7. Shadrikov V. D. Psychological activity and abilities of the person. - M.: Publishing Corporation "Logos", 1996. - 320 p.

8. Shchukina G. I. Activation of cognitive activity of students in the educational process Text. / G. I. Schukina. M.: Education, 2011. -134 p.

9. Ellis R. The Study of Second Language Acquisition Text. / R. Ellis. Oxford, 2010.P -204.

10.Palmer H. The Scientific Study and Teaching of Language Text. / H. Palmer. London, 2012. - 137 p. 